\title{
Combined Endoscopic-Laparoscopic Resection of Colon Polyps
}

\author{
Dieter Hahnloser \\ Department of Visceral Surgery, University Hospital Lausanne, Lausanne, Switzerland
}

\section{Key Words}

Endoscopy $\cdot$ Laparoscopy $\cdot$ Polyps $\cdot$ Surgery

\begin{abstract}
Aims: To analyze the current literature on combined endoscopic-laparoscopic resection of colon polyps and to compare this new approach to standard laparoscopic colonic resection for polyps not suitable for endoscopic resection. $\boldsymbol{R} \boldsymbol{e}$ sults: Several studies demonstrated that with a combined endoscopic-laparoscopic approach, polyps were successfully resected in $82-91 \%$ with a low morbidity of 3-10\% and a short hospital stay of 1-2 days. Segmental laparoscopic resection was necessary in only $9-12 \%$, but had a conversion rate to open surgery of $15 \%$ with an average hospital stay of 6-11 days. A cancerous polyp was found in 6-13\% after a combined approach, with lymph node metastasis in $6 \%$. Recurrent polyps after a combined endoscopic-laparoscopic resection seem to be rare, but follow-up of most studies is short and incomplete. Conclusion: Combined endoscopiclaparoscopic resection of colon polyps is feasible, safe, and has a high success rate. Malignant lesions can be treated laparoscopically during the same operation, avoiding the need for a second procedure, and with good long-term oncologic outcome.

Copyright $\odot 2012$ S. Karger AG, Basel
\end{abstract}

(C) 2012 S. Karger AG, Basel

0257-2753/12/0308-0081\$38.00/0

Fax +4161306 1234

E-Mail karger@karger.ch

www.karger.com
Accessible online at: www.karger.com/ddi

\section{Introduction}

Colon polyps are generally removed endoscopically with low complication rates. Postpolypectomy perforation of the colon secondary to either manipulation or cautery effects occur in $0.1-3.0 \%$ [1]. In case of perforation, surgical intervention is frequently required with its associated morbidity. Colon polyps larger than $2.5 \mathrm{~cm}$ in diameter harbor malignant transformation in $34 \%$ and polyps larger than $3 \mathrm{~cm}$ can be completely excised in only $67-75 \%$ of the cases, thus questioning the endoscopic approach $[2,3]$. In addition, a variety of 'difficult polyps' are not accessible for colonoscopic removal because of their size, broad base, or difficult location (impossible to see the polyp's base, polyps behind mucosal folds or in tortuous colonic segments).

Combined endoscopic-laparoscopic resection allows a more 'aggressive' endoscopic polypectomy. Laparoscopy can help to maneuver the colon into a more favorable position for endoscopic polypectomy and to examine the serosal surface to rule out perforation after polypectomy. This allows the endoscopist to be more 'aggressive' during polypectomy, ensuring complete resection of the polyp. In addition, if the polyp cannot be removed endoscopically, perforation occurs, or if the instantaneous section demonstrates invasive cancer, patients can be

Prof. Dr. med. Dieter Hahnloser, EBSQ Coloproctology

University Hospital Lausanne, Department of Visceral Surgery

Rue du Bugnon 46

$\mathrm{CH}-1011$ Lausanne (Switzerland)

Tel. +41 21314 2406, E-Mail dieter.hahnloser@ chuv.ch 
treated with laparoscopic surgery during the same intervention.

The aims of this review are to analyze the current literature on combined endoscopic-laparoscopic resection of colon polyps, and to compare this new approach to standard laparoscopic colonic resection for polyps not suitable for endoscopic resection.

\section{Results of Laparoscopic Resection of Colonic Polyps}

Within the last 10 years, laparoscopic surgery has gained a substantial significance for the treatment of colorectal tumors. The potential advantages of a laparoscopy resection are a fast postoperative recovery, a low rate of incisional hernia, and the reduction of peritoneal adhesion. A number of randomized controlled trials have demonstrated that laparoscopic resection of colon cancer is not only safe with all the known patient benefits of a minimal invasive approach, but is also oncologically adequate in experienced hand [4-7].

Large polyps that occupy more than one third of the bowel circumference or that span two haustral folds, for example, were generally considered unsuitable for endoscopic resection and were sent for surgical resection. Table 1 lists results of several studies of laparoscopic resection of colonic polyps. Most polyps were located in the sigmoid colon (36\%) [8] or in the right colon (66\%) [9]. Operating time of laparoscopic colon resections ranged from 87 to 199 min with a conversion rate to open surgery of $3-10 \%$. Morbidity was low between 9 and $21 \%$, but can include severe complications such as anastomotic leak. Hospital stay is reported to be 3-11 days. In a study of 51 consecutive patients, 4 patients were readmitted $(7.8 \%)$ and 2 patients were reoperated (3.9\%) [10].

The mean size of the resected polyps were 2.0 [11] to $3.1 \mathrm{~cm} \mathrm{[10].} \mathrm{In} \mathrm{the} \mathrm{largest} \mathrm{series} \mathrm{of} 525$ patients, the overall incidence of cancer was 18.1\% (T1: 44.2\%, T2: 37.9\%, T3: $16.8 \%$, and T4: $1.1 \%$ ) [8]. The median number of lymph nodes removed was 13 and lymph node metastasis was found in 14 patients $(14.8 \% ; 4.8 \%$ in $\mathrm{T} 1,19.4 \%$ in $\mathrm{T} 2$, $25 \%$ in $\mathrm{T} 3$, and $100 \%$ in T4). The carcinomas were predominantly located in the sigmoid colon (47.5\%). In another study, 35 patients (44.3\%) had invasive cancer, 27 of the patients had T1 and 2 patients T2 [11]. In view of this high rate of malignant transformation and the absence of unequivocal factors predictive of already malignant transformation, an oncologically radical operation is essential if a laparoscopic resection is performed.

\section{Set-Up and Technique of Combined Endoscopic- Laparoscopic Resection for Colonic Polyps}

For a combined approach the patients need preoperative colonic cleansing and general anesthesia. In general, the intervention starts with a laparoscopic exploration of the abdomen and if needed adhesiolysis. Colonoscopy is performed next, frequently aided by laparoscopic manipulation or mobilization of the colon. Resection of the polyp can then be performed according the several techniques as described by Wilhelm et al. [12]: (1) Laparoscopic-assisted endoscopic resection: $5 \%$ of patient; (2) endoscopic-assisted wedge resection: $49 \%$ of patient; (3) endoscopic-assisted transluminal resection: $27 \%$ of patients, and (4) endoscopic-assisted segmental resection: for lesions not accessible to laparoscopic-assisted endoscopic resection, endoscopicassisted segmental resection, or endoscopic-assisted transluminal resection. A segmental laparoscopic resection was performed under endoscopic guidance.

If a colonic defect occurs, it can be closed by laparoscopic suturing or by using the TAS system (Ethicon Endosurgery, Cincinatti, Ohio, USA) under laparoscopic guidance. This was successful in 7 out of 8 patients [13].

\section{Results of the Combined Endoscopic-Laparoscopic Approach}

In a series of 251 polyps, most polyps resected were located in the right (59\%) and rectosigmoid colon (19\%). Mean operating time was $96 \mathrm{~min}$ with an estimated blood loss of $46 \mathrm{ml}$. Serosal suturing was necessary in 10\%. Intraoperative complications were very rare and were mainly dependent on the need for a surgical segmental or an anatomical resection. The main indications for surgical resection were the finding of a cancerous polyp in $5-11 \%$. Successful endoscopic polypectomy could be performed in 11 out of 19 patients (58\%), suggesting that many endoscopically 'unresectable' polyps can, in fact, be resected endoscopically. Table 2 lists the success rates of such a combined approach.

Operating time of a combined approach ranged from 45 to $100 \mathrm{~min}$ and the mean hospital stay of the largest series [14] was 1.1 day with a return to full activity after 2 days (range: 1-10 days). Morbidities were minor (grade 1) in most cases and included wound/port infection, urinary tract infections, postoperative paralytic ileus, and bleeding. Intra-abdominal abscesses occurred in 5 out of 146 patients (3.4\%) necessitating CT-guided drainage in 3 patients and reoperation in 1 case [12]. One pa- 
Table 1. Results of laparoscopic resection of colonic polyps not suitable for endoscopic polypectomy

\begin{tabular}{|c|c|c|c|c|c|c|c|}
\hline Pokala (2007) [10] & 51 & 87 & 3 & 10 & 18 & 20 & NA \\
\hline Benedix (2008) [8] & 525 & 150 & 11 & 3.2 & 20.8 & 18.1 & 14.8 \\
\hline Hauenschild (2009) [17] & 58 & 199 & 9 & 7 & 9 & 0 & - \\
\hline $\operatorname{Itah}(2009)[9]$ & 64 & 140 & NA & 5 & NA & 14 & 33 \\
\hline
\end{tabular}

$\mathrm{NA}=$ Not available; $\mathrm{N}+=$ positive lymph nodes.

Table 2. Success rates of combined endoscopic-laparoscopic resection of colonic polyps

\begin{tabular}{|c|c|c|c|c|c|c|}
\hline Study, first author & $\begin{array}{l}\text { Patients } \\
\text { (polyps), n }\end{array}$ & $\begin{array}{l}\text { Successful endoscopic } \\
\text { resection, \% }\end{array}$ & $\begin{array}{l}\text { Cancer } \\
\%\end{array}$ & $\begin{array}{l}\mathrm{N}+ \\
\%\end{array}$ & $\begin{array}{l}\text { Total laparoscopic } \\
\text { resection required, \% }\end{array}$ & $\begin{array}{l}\text { Conversion to } \\
\text { open surgery, } \%\end{array}$ \\
\hline Wilhelm (2009) [12] & $146(154)$ & 82 & 11 & 5.8 & 18 & 19 \\
\hline Franklin (2009) [14] & $160(209)$ & 91 & 7 & 0 & 14 & NA \\
\hline Agrawal (2010) [13] & $19(19)$ & 26 & 5 & 0 & 32 & NA \\
\hline Wood (2011) [18] & $13(16)$ & 77 & 8 & NA & 23 & 33 \\
\hline Grünhagen (2011) [16] & $11(11)$ & 91 & 0 & - & 9 & 0 \\
\hline Yan (2011) [15] & 23 (all right colon) & 87 & 0 & 0 & 13 & 0 \\
\hline
\end{tabular}

NA $=$ Not available.

tient with generalized peritonitis due to anastomotic leak died on postoperative day 12 , accounting for a mortality rate of $0.7 \%$.

After a mean colonoscopic follow-up of 2.9 years $( \pm 2.3)$, 31 patients (29\% of patients with colonic follow-up) developed a metachronous adenoma [12]. Eight out of these showed macroscopic or microscopic characteristics of advanced lesions (i.e. $>10 \mathrm{~mm}$, villous component, highgrade dysplasia, or cancer). The recurrence-free fraction at 36 months in another study was 55.7\% (95\% CI: 8.6-87.0\%) [15]. All de novo polyps were benign and could be removed successfully with snare polypectomy. Three other studies had no recurrence at mean follow-up of 65 months [14], 11 months [16], and 3 months [13], respectively.

\section{Comparison of Combined Endoscopic-Laparoscopic Resection versus Laparoscopic Segmental Resection}

To date, there have been no randomized or comparative series of the combined approach versus a standard laparoscopic resection of colonic polyps. Most likely, the herein presented studies also do not reflect homogenous groups as the percentages of cancerous polyps and the presence of nodal metastasis were different (14-44\% cancer and $9-33 \% \mathrm{~N}+$ in the primary laparoscopic segmental resection patients versus $5-11 \%$ cancer and $6 \% \mathrm{~N}+$ in the studies of the combined approach). Nevertheless, the polyps were successfully resected in $82-91 \%$ in the studies of a combined approach with a low morbidity of $3-10 \%$ and a short hospital stay of 1-2 days. Segmental laparoscopic resection was necessary in only $9-12 \%$, but had a conversion rate to open surgery of $15 \%$ with an average hospital stay of 6-11 days. Recurrences were rare with $2-5 \%$. Of note, follow-up times of the combined approach were short and not always complete. On the other hand, success rate in regard to recurrence of colonic polyp after laparoscopic resection is by definition $0 \%$ (because of the resection of the colon) and patients do not need to undergo a second operation in case of malignancy in the final histology.

Studies of a combined approach indicate that patients with polyps primarily judged unsuitable for endoscopic resection and who undergo a combined endoscopic-lap- 
aroscopic approach have high success rates, reducing the rate of segmental colonic resection. However, both the surgeon and the patient have to be aware that the decision of the ideal resection technique can only be made intraoperatively. Furthermore, the patient has to be informed that a second oncological resection might be necessary depending on the final histology.

\section{Conclusions}

Combined endoscopic-laparoscopic resection of colonic polyps can be performed safely with a high success rate in selected patients. Malignant lesions identified during the procedure can be treated oncologically adequate- ly by laparoscopy during the same operation, avoiding the need for a second procedure. Prerequisites are the availability of intraoperative colonoscopy and laparoscopy as well as the possibility of an instantaneous section. A combined endoscopic-laparoscopic approach is an effective treatment for large, inaccessible colonic polyps that would otherwise be treated by colonic resection, and should be considered in every patient.

\section{Disclosure Statement}

The author declares that no financial or other conflict of interest exists in relation to the content of the article.

\section{References}

1 Lohsiriwat V: Colonoscopic perforation: incidence, risk factors, management and outcome. World J Gastroenterol 2010;16:425430.

2 Dell'Abate P, et al: Endoscopic treatment of colorectal benign-appearing lesions $3 \mathrm{~cm}$ or larger: techniques and outcome. Dis Colon Rectum 2001;44:112-118.

-3 Nusko G, et al: Risk of invasive carcinoma in colorectal adenomas assessed by size and site. Int J Colorectal Dis 1997;12:267-271.

4 Laparoscopically assisted colectomy is as safe and effective as open colectomy in people with colon cancer. Abstracted from: Nelson H, Sargent D, Wieand HS, et al; for the Clinical Outcomes of Surgical Therapy Study Group. A comparison of laparoscopically assisted and open colectomy for colon cancer. N Engl J Med 2004;350:2050-2059. Cancer Treat Rev 2004;30:707-709.

5 Buunen M, et al: Survival after laparoscopic surgery versus open surgery for colon cancer: long-term outcome of a randomised clinical trial. Lancet Oncol 2009;10:44-52.
6 Fleshman J, et al: Laparoscopic colectomy for cancer is not inferior to open surgery based on 5-year data from the COST Study Group trial. Ann Surg 2007;246:655-662, discussion 662-664.

7 Jayne DG, et al: Five-year follow-up of the Medical Research Council CLASICC trial of laparoscopically assisted versus open surgery for colorectal cancer. Br J Surg 2010;97: 1638-1645.

8 Benedix F, et al: Laparoscopic resection for endoscopically unresectable colorectal polyps: analysis of 525 patients. Surg Endosc 2008;22:2576-2582.

-9 Itah R, et al: Laparoscopic surgery for colorectal polyps. JSLS 2009;13:555-559.

10 Pokala N, et al: Outcome of laparoscopic colectomy for polyps not suitable for endoscopic resection. Surg Endosc 2007;21:400-403.

11 Lai JH, et al: Laparoscopic resection for colorectal polyps: a single institution experience. ANZ J Surg 2011;81:275-280.

$\checkmark 12$ Wilhelm D, et al: Combined laparoscopicendoscopic resections of colorectal polyps: 10 -year experience and follow-up. Surg Endosc 2009;23:688-693.
13 Agrawal D, et al: Endoscopic mucosal resection with full-thickness closure for difficult polyps: a prospective clinical trial. Gastrointest Endosc 2010;71:1082-1088.

14 Franklin ME Jr, Portillo G: Laparoscopic monitored colonoscopic polypectomy: longterm follow-up. World J Surg 2009;33:13061309.

15 Yan J, et al: Treatment for right colon polyps not removable using standard colonoscopy: combined laparoscopic-colonoscopic approach. Dis Colon Rectum 2011;54:753-758.

16 Grünhagen DJ, et al: Laparoscopic-monitored colonoscopic polypectomy: a multimodality method to avoid segmental colon resection. Colorectal Dis 2011;13:12801284.

17 Hauenschild L, et al: Laparoscopic colorectal resection for benign polyps not suitable for endoscopic polypectomy. Int $\mathrm{J}$ Colorectal Dis 2009;24:755-759.

18 Wood JJ, et al: Laparo-endoscopic resection for extensive and inaccessible colorectal polyps: a feasible and safe procedure. Ann R Coll Surg Engl 2011;93:241-245. 